\title{
O CIDADÃO COM TRANSTORNO PSÍQUICO: REFLEXÕES SOBRE OS DIREITOS HUMANOS E OS DIREITOS DO PACIENTE
}

\author{
CITIZEN WITH PSYCHOLOGICAL DISTRACTION: \\ REFLECTIONS ABOUT HUMAN RIGHTS AND THE PATIENT'S RIGHTS
}

Rita de Cássia Chamma* Hideko Takeuchi Forcella**

CHAMMA, RC; FORCELLA, HT. O cidadão com transtorno psíquico: reflexões sobre os direitos humanos e os direitos do paciente. Rev Esc Enf USP, v. 35, n. 2, p. 184-90, jun. 2001.

\begin{abstract}
RESUMO
Considerando, as transformações sócio-politico-econômicas que vem ocorrendo, a construção da história da Enfermagem Psiquiátrica, bem como as modificações no ensino de enfermagem pela nova Lei de Diretrizes e Bases e, ainda, a preocupação existente por parte de algumas facções no que se refere ao cumprimento e ao respeito aos Direitos Humanos e Direitos do Paciente, este estudo propõe reflexões sobre as condutas éticas de profissionais de enfermagem em relação ao paciente internado em hospital psiquiátrico, ressaltando o respeito pela dignidade humana. A discussão se dá à luz da Cartilha dos Direitos do Paciente, proposta pela Secretaria de Estado da Saúde do Governo do Estado de São Paulo e da Declaração Universal dos Direitos Humanos. Dá destaque à responsabilidade da área do ensino no tocante ao processo de mobilização para a transformação de preconceitos sobre a loucura, buscando a prática efetiva regida pelos princípios de igualdade, democracia, liberdade e exercício da cidadania.
\end{abstract}

PALAVRAS -CHAVE: Enfermagem psiquiátrica. Direitos humanos. Direitos dos pacientes.

\section{ABSTRACT}

Considering the social, political and economical changes such as occured during the construction of the Psychiatric Nursing History, as well as the ongoing modifications in teaching nursing due the new Law for Directories and Bases, and taking also into account the existing preoccupation of some sections as far as the compliance with the Human Rights and Patient Rights are concerned, the present study proposes some reflections about the ethical conducts by nursing professionals in relation to patients interned in Psychiatric Hospitals, giving emphasis to the aspects related to the human dignity. The discussion is based in the Directory of the Rights of Patients proposed by the Secretary of Health of the Government of the State of Seto Paulo, as well as the Universal Declaration of Human Rights. The study gives furthermore emphasis to the responsability in the area of teaching as far as the mobilization process for transforming the preconceptions regarding the mental diseases are concerned and examines the effective practice of equality, democracy, liberty and the exercise of the citizenship of the patient.

KEYWORDS: Psychiatric nursing. Human rights. Patient advocacy.

\section{INTRODUÇÃO}

De acordo com BARROS (1996) a noção de reabilitação implantada pelo processo de desinstitucionalização

"irá em busca da reconstrução das histórias de vida, procurando recuperar ou criar vinculos e condições materiais, sociais $e$

emocionais para que se possa romper com a lógica da reprodução das relações de dependência. Não se trata de soluções concretas para cada individuo, uma vez que garantidos seus direitos essenciais como moradia, liberdade, trabalho"...

\footnotetext{
* Enfermeira. Aluna do Programa de Pós-Graduação em nível de Doutorado da Escola de Enfermagem da USE

** Enfermeira. Docente da disciplina de Pós-Graduação "Evolução Histórico-Social da Assistência em Saúde Mental".
} 
Situações de desrespeito, discriminações em diversos niveis, preconceitos e maus tratos a pacientes de modo geral e, em especial, àqueles internados em hospital psiquiátrico, têm sido, comumente, detectados por meio de denúncias e posterior sindicância pelos órgãos competentes, como a Unidade de Fiscalização do Conselho Regional de Enfermagem de São Paulo (COREN-SP), Comissões de Ética de Enfermagem e Câmara Técnica de Enfermagem do COREN-SP, nas quais uma das autoras do presente artigo tem trabalhado incansavelmente em prol do bem-estar dos pacientes.

A preocupação por tal constatação resultou em um estudo que teve a finalidade de alertar a comunidade de enfermeiros sobre a assistência proporcionada ao doente psiquiátrico que tem direito à dignidade e à cidadania como qualquer outro cidadão que tem seus direitos humanos respeitados e preservados.

Além disso, episódios de maus tratos a pacientes internados em hospitais psiquiátricos, bem como as más condições apresentadas por tais instituições, têm sido noticiados pela mídia com bastante freqüência, tornando-se um problema nacional, de dimensões bem maiores do que simplesmente relacionado à área da enfermagem.

A atual Reforma Psiquiátrica no Brasil, que tem como finalidade a construção de um processo de reformulação social e crítica da "loucura", iniciou-se a partir de denúncias feitas por meio da mídia sobre o tratamento inadequado proporcionado aos doentes internados em hospitais psiquiátricos, salientando as más condições de vida nas instituições, a superlotação de pacientes e o número insuficiente de profissionais (SILVA; VIANNA, 1999).

Em relação às políticas de Saúde Mental no Brasil, em 1989 o deputado Paulo Delgado apresentou ao Congresso Nacional, o Projeto de Lei $n^{\circ} 3657 / 89$ que dispõe sobre a extinção progressiva dos hospitais psiquiátricos e sua substituição por serviços alternativos de atendimento, regulamentado a internação psiquiátrica compulsória, projeto esse encaminhado ao Senado Federal em 1991 (DELGADO, 1992).

Referindo-se ao Projeto, BEZERRA JUNIOR (1992) relata que

"não institui um modelo terapêutico, não desaparece com as internações, não propõe a ressocialização compulsória dos milhares de brasileiros há anos internados - apenas põe uma pedra no processo de reprodução da situação horrorosa que hoje vigora. Nada garante acerca da qualidade da assistência, mas aumenta as possibilidades de reforçar as experiências mais bem sucedidas. Deixa intactas questões cruciais como a garantia dos direitos daqueles a quem a sociedade transformou em população asilar, ou a necessidade de novos currículos na formação de profissionais. Mas oferece pela primeira vez um instrumento legal de defesa dos direitos civis dos pacientes" (grifo nosso).

A partir daí, muitos movimentos em prol da humanização da assistência a pessoa com transtorno mental aconteceram como a I Conferência Nacional de Saúde Mental, em 1987 que, segundo AMARANTE (1995), teve como recomendações o combate à psiquiatrização social através de práticas alternativas em saúde mental, a participação da comunidade na elaboração e implementação de políticas de saúde mental bem como o reconhecimento pelo Estado da participação da população no processo decisório, além do incentivo para investimentos na área extrahospitalar.

Ainda como movimentos em prol da Reforma Psiquiátrica no Brasil, houve a II Conferência Nacional de Saúde Mental, realizada em 1992, em Brasília, com a participação de vários segmentos sociais. O evento foi significativo e decisivo na nova trajetória da assistência psiquiátrica no Brasil. Teve como ternário a rede de atenção em Saúde Mental, a transformação e o cumprimento de leis e o direito à atenção e o direito à cidadania.

AMARANTE (1992), referindo-se a II Conferência Nacional de Saúde Mental, declara

"... é quando a psiquiatria e as instituições psiquiátricas deixam de ser propriedade exclusiva de psiquiatras e de profissionais de saúde ou ainda, quando a discussão sobre a loucura e o sofrimento psíquico deixam de ser objetos privados dos técnicos e administradores, para serem assumidas enquanto questões da vida, dos direitos das pessoas, da cidadania".

Vale ressaltar que, modelos de Reabilitação Psicossocial têm sido implantados com a finalidade precípua de resgatar a cidadania do paciente. Neste sentido, a Reabilitação Psicossocial tem como metas: diminuir o sofrimento, desidentificar a pessoa da doença, neutralizar processos crônicos, aumentar a articulação social do sujeito com o ambiente, ampliar a capacidade de autonomia para a vida, ampliar as oportunidades e aumentar o poder de contratualidade social.

A história da Enfermagem Psiquiátrica nos mostra, por sua vez, que, apesar das transformações 
sócio-politico-econômicas e culturais ocorridas através dos tempos, dos movimentos das Politicas de Saúde Mental, da Reforma Psiquiátrica, das Conferências de Saúde Mental, da Reabilitação Psicossocial e da preocupação de alguns segmentos no que se refere ao cumprimento e respeito aos Direitos Humanos e Direitos do Paciente, a prática de enfermagem psiquiátrica parece não estar acompanhando efetivamente tais movimentos. Mantém ainda como seu objeto, o corpo e a doença, ao invés do individuo como um todo (BARROS, 1996).

Por outro lado, apesar das modificações que estão sendo realizadas no ensino de uma forma geral pela nova Lei de Diretrizes e Bases (LDB), tem-se ainda observado falhas que configuram as situações preocupantes, referidas anteriormente, cometidas pelos profissionais durante suas práticas que, também, podem ser atribuídas à deficiência no ensino da Enfermagem Psiquiátrica bem como da Ética, seja na graduação ou no ensino médio da Enfermagem com o agravante da ausência da Disciplina Enfermagem Psiquiátrica no currículo mínimo do Curso de Auxiliar de Enfermagem, que é o maior contingente de profissionais, lotados nas diversas instituições psiquiátricas.

O ensino da Enfermagem Psiquiátrica, desde os primórdios, esteve calcado nos moldes asilares, onde predominava o confinamento e a vigilância, constituindo impeditivo para a melhoria da qualidade da assistência de enfermagem nessa especialidade.

À análise dos conteúdos programáticos de 22 Disciplinas de Enfermagem Psiquiátrica, no período compreendido entre 1930 e 1964, elaborada por FERNANDES (1982), mostra que o ensino deteve-se nos aspectos clínicos da doença, caracterizando-se como biologicista e hospitalocêntrico. Após 1964, os programas de ensino começaram a considerar novas possibilidades, contando com o desenvolvimento da psicanálise, das correntes psicológicas, com a valorização dos aspectos psicológicos do comportamento humano. Porém, os campos de ensino teórico-prático continuam sendo predominantemente os hospitais e as atividades discentes, biologicistas e individuais.

Partindo do pressuposto de que a ocorrência de tais condutas caracterizadas como não aceitas eticamente, tem se mantido e, tendo em vista documentos que defendem os direitos humanos, os direitos do paciente, a dignidade e a ética humana e, acreditando ser o conhecimento destes aspectos essenciais para o exercício da enfermagem psiquiátrica, propusemo-nos, neste estudo, realizar uma discussão sobre tais condutas em consonância com os movimentos de proteção e respeito à dignidade humana, tendo como principal eixo condutor a ética do ser humano, supostamente esperada como adequada, adotada pelos profissionais das diferentes categorias de enfermagem que atuam na área de Psiquiatria.

\section{OBJETIVO}

- Refletir sobre condutas éticas de profissionais de enfermagem em relação ao paciente internado em Hospital Psiquiátrico, levando em consideração aspectos relativos ao respeito pela dignidade humana.

\section{DESENVOLVIMENTO}

A reflexão acerca das condutas de profissionais de enfermagem psiquiátrica ocorreu à luz da Declaração Universal de Direitos Humanos e da Cartilha dos Direitos do Paciente, proposta pela Secretaria de Estado da Saúde do Governo do Estado de São Paulo.

\section{DISCUSSÃO}

$\mathrm{Na}$ área de assistência em hospital geral, verificamos que, até hoje, os profissionais de enfermagem de todos os niveis, têm dificuldade de cuidar de pacientes que apresentam qualquer tipo de alteração de comportamento, chegando até mesmo a recusar cuidar dos mesmos denotando rejeição e cometendo, às vezes, atos de negligência. Temos observado, ainda, que a falta de cuidado chega até ao não atendimento das necessidades básicas como higiene e alimentação.

Em pronto-socorro, de uma forma geral, a situação é ainda mais lamentável, pois além dos pacientes tidos como "loucos" ficarem juntos aos considerados "normais", são abordados por alguns profissionais da enfermagem, com linguagem chula, chegando, muitas vezes, a humilhá-los e a constrangêlos.

Apesar de vivenciar algumas tentativas na direção do cuidado humanizado ao paciente psiquiátrico, não tivemos oportunidade de observar a equipe de Enfermagem interagindo terapeuticamente com o doente e sim utilizando abordagens permeadas de atitudes que denotam rejeição, repulsa e preconceito, havendo empenho muito grande para a transferência imediata destes pacientes para unidades especializadas.

Em geral, os enfermeiros que trabalham na área de psiquiatria são solicitados por unidades das demais especialidades médicas para ministrar medicamento aos pacientes com transtornos psíquicos ou 
A precária assistência prestada ao paciente psiquiátrico tem sido motivo de estudos realizados por enfermeiros, especialmente em relação as falhas observadas no seu atendimento, sobretudo a notória indiferença que permeia o relacionamento profissionaldoente (CHAMMA, 1997).

Por outro lado, nos serviços de saúde, alguns profissionais adotam condutas individualistas, onipotentes e arrogantes no trato com o paciente, manifestando falta de respeito, preconceito e discriminação, esquecendo-se dos direitos humanos e dos direitos do consumidor e provocando atendimento desumano e de péssima qualidade.

Tal aspecto estende-se também à família do paciente, que é tratada, na maioria das vezes, com descaso, desatenção e desrespeito.. Conduta que dificulta a recuperação do doente, dada a ansiedade gerada pela situação de isolamento que o impede de estar ao lado de pessoas significativas para ele. Ainda, é nítida a conduta autoritária por parte de alguns profissional de enfermagem diante da família, exercendo um poder perverso, sonegando informações e orientações que poderiam ajudar no processo terapêutico e de recuperação do doente.

Do mesmo modo, os comentários inadequados e as abordagens que não levam em consideração o nível de compreensão do paciente, certamente são fatores que denigrem a imagem do profissional e da profissão. Além disso, o enfermeiro, muitas vezes utiliza linguagem técnica, incompreensivel para o leigo e, outras vezes, a relação é permeada por um mutismo angustiante, que provoca ansiedade no paciente e, conseqüentemente, retrocesso em sua recuperação.

De fato, não se tem dado atenção ao efeito que os nossos pensamentos, palavras e ações provocam na vida das pessoas. Rouba-se o direito que o paciente tem sobre seu próprio corpo. Por isso, há necessidade de realizarmos uma profunda reflexão a respeito da atitude preconceituosa e ações discriminatórias que hoje em dia tem-se adotado.

Assim, fica cada vez mais dificil perceber uma assistência individualizada, que assegure ao paciente privacidade e respeite seus valores culturais, econômicos e religiosos.

Evidentemente, tal situação só poderá ser revertida à medida em que houver uma reflexão sobre as questões éticas que norteiam a prática profissional, acompanhada de exercícios contínuos de autoavaliação de cada um dos profissionais da saúde dos diversos serviços em que estão lotados.

O direito à saúde permeia a dimensão da dignidade do ser humano e o respeito a esse direito não é simplesmente uma questão de solidariedade ou de cidadania, mas antes de tudo, de sobrevivência de toda uma nação.
Para auxiliar na reflexão sobre o tema, do preâmbulo da Declaração Universal de Direitos Humanos, duas considerações devem ser destacadas:

"Considerando que a liberdade, a justiça

e a paz no mundo têm por base o reconhecimento da dignidade intrinseca $e$ dos direitos iguais e inalienáveis de todos os membros da família humana" ;

"Considerando que o desconhecimento e o menosprezo dos direitos humanos tem originado atos de barbárie ultrajantes para a consciência da humanidade; e que se tem proclamado, como a aspiração mais elevada do homem, um mundo em que os seres humanos, liberados do temor e da miséria, desfrutem da liberdade da palavra e da liberdade de crenças".

Ainda, consideramos nesta reflexão a Declaração Universal dos Direitos Humanos, adotada e proclamada em 1948, definida coletivamente, no momento em que o mundo acabava de presenciar a barbárie nazista, adotada como base para salvaguardar a dignidade humana.

Outrossim, diferentes países, dentre eles, o Brasil, manifestam a aceitação do conjunto dos direitos humanos baseado nos princípios da dignidade humana, consolidado passo a passo, reconhecendo liberdades individuais, direitos civis, direitos sociais e direito à vida sem violência.

Também, todos os seres humanos têm direitos pelo fato de serem gente, independente de sua origem étnica, nacionalidade, crença, classe social entre outros.

Desse modo, na medida em que o Brasil responsabilizou-se em compromissos internacionais pela garantia dos direitos e incorporou a noção de igualdade e justiça na Constituição, assumindo o Programa de Direitos Humanos, selou um compromisso expresso e formal. No entanto, nunca se vislumbrou índices de desigualdade tão grandes como os que temos presenciado atualmente.

É preciso que se assimile efetivamente o significado dos direitos humanos, exigindo cidadania plena e dignidade para todos, seja legalmente, seja no cotidiano.

O caminho para que isso aconteça permeia o direito à cidadania para todos, não apenas para os iguais mas, sobretudo, para os diferentes. Conduzirse, respeitando as diferenças é a verdadeira democracia na busca de um mundo mais justo.

Vale citar ainda a DECLARAÇÃO DE MEDELLIN - "Melhor qualidade de vida para os habitantes das Américas no século XXI", em seus considerandos: 
1- Que os componentes do desenvolvimento humano e a qualidade de vida estão intimamente relacionados com os direitos e deveres cidadãos reconhecidos em todos os países das Américas;

2- (...)

3- (...)

4- Que o contexto atual nos nossos países indica que se adentra ao terceiro milênio com os seguintes desafios:

- alcançar a equidade de acesso a bens e direitos, para reduzir efetivamente toda forma de exclusão social;

- buscar a convivência baseada no respeito efetivo aos direitos humanos, que reconstrua o tecido social com base na tolerância e solidariedade, como uma forma de enfrentar os diferentes tipos de violência em nossos países;

5- Que a finalidade precipua dos Municípios e Comunidades Saudáveis seja tornar possivel que os seres humanos alcancem seu direito a ser cada vez mais saudável a ter uma melhor qualidade de vida no século XXI.

E, assim declara,

$1-(.$.

2- Implementar políticas públicas saudáveis no âmbito local, de educação, emprego, vivenda, saúde, nutrição, paz, convivência, qualidade dos transportes, serviços públicos, utilização adequada do espaço público, e ambiente, entre outras, que busquem o melhoramento das condições devida e da população, a partir de suas necessidades balizadas pelas politicas internacionais e nacionais;

3- (...)

4- Promover a busca de novos modelos econômicos ou a revisão e modificação dos atuais, de forma a permitir a reativação e o crescimento econômico, para garantir a equidade social, o acesso universal aos serviços, ao desenvolvimento tecnológico e ao progresso científico e cultural.

4- (...)

$5-(\ldots)$

6- Estimular intervenções multissetoriais em âmbito municipal dirigidas aos determinantes dos diferentes tipos de violência, baseadas na defesa dos direitos humanos e como práticas pacíficas;

7- Contribuir para o combate à corrupção em âmbito municipal, construindo uma ética civil reitora de diferentes formas de relação entre as pessoas e organizações;

8- Procurar a convergência de movimentos em âmbito municipal das Américas, que tenham metas comuns, orientadas para o melhoramento da qualidade de vida, utilizando o conceito holístico de saúde como fio condutor. .
A defesa do protagonismo e o respeito pelos direitos e deveres das comunidades locais, devem ser parâmetros para que a sociedade do novo século seja mais equilibrada e justa.

A Cartilha dos Direitos do Paciente propostos pela Secretaria de Estado da Saúde do Governo do Estado de São Paulo, incentiva a humanização no atendimento, à medida em que amplia os direitos dos pacientes, que devem ser encarados como individuos ativos, participante do processo de responsabilização pelo tratamento proposto.

Os hospitais psiquiátricos, por sua vez, no decorrer da história, têm se caracterizado pelo desrespeito aos direitos humanos e direitos dos pacientes, pois entre outros aspectos, isolam o paciente do seu meio social e familiar, além do pouco apoio oferecido aos familiares para que possam ter condições de cooperar no processo terapêutico.

A luta antimanicomial é caracterizada pela defesa de tratamentos mais eficientes que possibilitem a reinserção do indivíduo com transtorno psíquico na sociedade, permitindo a manutenção de seus vínculos pessoais e valorizando sua experiência de vida.

Assim, o profissional de enfermagem ganha novos desafios. Desempenha papel importante, à medida em que participa na consolidação do novo modelo de atendimento psiquiátrico e tenta aumentar os laços sociais e a rede de apoio ao usuário.

\section{CONSIDERAÇÕES FINAIS}

Saúde Mental não é apenas o contrário de doença mental. Em seu conceito mais profundo está implícito o respeito ao direito à dignidade humana. Isto significa uma vida sem preconceitos, sem discriminações e sem violência em qualquer nível.

Assim, as instituições de assistência psiquiátrica deveriam definir e implantar critérios para admissão de pessoal, tanto daqueles de niveis médio quanto superior, oferecendo treinamento, atualização e educação em serviço aos profissionais admitidos, condições necessárias, que ajudam na garantia da qualidade da assistência de Enfermagem Psiquiátrica e de Saúde Mental.

Por outro lado, a responsabilidade da área do ensino é grande, uma vez que deve considerar a necessidade da formulação de diretrizes para o ensino de Enfermagem Psiquiátrica e de Saúde Mental, buscando eliminar a dicotomia existente entre a teoria e a prática da especialidade.

Tal responsabilidade, mesmo que parcial, estende-se ao processo de incentivo à mobilização, fundamental para a transformação do conceito de loucura do senso comum, que entre outros aspectos, 
visa evitar o isolamento do paciente e ajudá-lo a tomar consciência do direito de exercer, de fato, sua cidadania.

Em suma,

"Até quando as propostas idealistas que permeiam os principios de igualdade, democracia, liberdade ficarão no plano virtual, na dimensão dogmática, resultando em sofrimento?" "Será que não há salvação, já que tudo se justifica em nome da verdade? E, é ela única?"

Sabe-se que o movimento e o processo criativo não findam com a produção criada, portanto, não se esgotam jamais. Há busca incessante do novo, do desconhecido, da inovação. Todavia, há um aspecto essencial para que a criatividade não adormeça - o

\section{REFERÊNCIAS BIBLIOGRÁFICAS}

AMARANTE, PD de C. (org). Loucos pela vida: a trajetória da reforma psiquiátrica no Brasil. Rio de Janeiro, SDE/ENSP, 1995.

AMARANTE, PD de C. A trajetória do pensamento crítico em saúde mental no Brasil: planejamento na desconstrução do aparato manicomial. In: ENCONTRO SAÚDE MENTAL E CIDADANIA NO CONTEXTO DOS SITEMAS LOCAIS DE SAÚDE. Santos, 1991. Anais. São Paulo, Hucitec/Cooperação Italiana em Saúde, 1992.

BARROS, S. O louco, a loucura e alienação institucional: o ensino de enfermagem psiquiátrica "sub judice". São Paulo, 1996. 229p. Tese (Doutorado) - Escola de Enfermagem, Universidade de São Paulo.

BEZERRA JUNIOR, B. Cidadania e loucura: um paradoxo? In: BEZERRA JUNIOR, B.; AMARANTE, P. (org). Psiquiatria sem hospicio. Rio de Janeiro: Relume Dumará, 1992.

CHAMMA, R de C. Ensino teórico-prático de enfermagem psiquiátrica e saúde mental nos cursos de graduação em enfermagem da grande São Paulo. São Paulo, 1997. 114p. Dissertação (Mestrado) - Escola de Enfermagem, Universidade de São Paulo.

CONFERÊNCIA NACIONAL DE SAÚDE MENTAL, 2, Brasília, 1992. Relatório Final. Brasilia: Ministério da Saúde, 1994.

CONFERENCIA NACIONAL DE SAÚDE MENTAL, 1, Brasília 1987. Relatório Final. Brasília: Ministério da Saúde, 1988.

DAWSON, R. No "magic" about mental nursing. _Nurs Mirror, v.313, n.7, p.30-1, 1970.

DELGADO, PGG. Reforma psiquiátrica e cidadania: o debate legislativo. Saúde em debate, n.35, p.80-4, 1992.

FERNANDES, JD. O ensino de enfermagem e de enfermagem psiquiátrica no Brasil. Salvador, 1982. $111 \mathrm{p}$. Dissertação (Mestrado) - Universidade Federal da Bahia. estimulo. E é este estimulo que buscamos constantemente a fim de criar novas alternativas de cuidar.

Não se tem pretensão de esgotar o assunto, mesmo porque nenhuma teoria foi construída e nenhuma proposta foi lançada como resultado deste estudo reflexivo. Pelo contrário, temos esperança que, profissionais criativos ou em busca da criatividade, sirvam-se desta leitura como estímulo para repensar as questões pontuadas, em conjunto ou individualmente para construírem algo novo, ou quem sabe, tornarem efetivo o que de bom e adequado já existe.

\section{"O importante é, tentar, ousar... Tentaremos fazer o mesmo..."}

Universal de Direitos Humanos Reflexão sobre a prática do ensino da enfermagem psiquiátrica e saúde mental. Rev Bras Enf, v.32, n.4, p.3-6, 1979.

FRAGA, MN de O. A prática de enfermagem psiquiátrica: subordinação e resistência. São Paulo, Cortez, 1993. cap.5, p.115-16: Condições de trabalho, consciência de classe e mecanismos de resistência.

GARCIA, ZHP. Opiniões do pessoal de enfermagem, da área médico-cirúrgica, sobre pacientes com perturbação mental. São Paulo, 1982. 79p. Dissertação (Mestrado) - Escola de Enfermagem, Universidade de São Paulo.

MIRANDA, CL. O parentesco imaginário. Rio de Janeiro, Cortez, 1993. Cap.1, p.11-21: Objeto e contexto.

SIlVA, AT de MC da; MELlo, IM de; MARTINS, PASF. Politicas de saúde mental no Brasil. São Paulo, EEUSP, 1999. / Mimeografado/.

SILVA, JP da; VIANNA, PC de M. Processo da reforma psiquiátrica no Brasil. São Paulo: EEUSP, 1999. / Mimeografado/.

SILVA, MCP. Análise do ensino da disciplina enfermagem psiquiátrica nos cursos de graduação em enfermagem da Grande São Paulo. São Paulo, 1991. 129 p. Dissertação (Mestrado), Escola de Enfermagem, Universidade de São Paulo.

VIGOTSKY, LS. O pensamento e a linguagem. São Paulo: Martins Fontes, 1991. 